\title{
Evaluasi Tutor Online untuk Meningkatkan Kualitas Layanan Tutorial Tatap Muka pada Pendidikan Jarak Jauh
}

\author{
Sugiran ${ }^{1)}$, Pardamean Daulay $^{2)}$, Badrus Zaman $^{3)}$, Faried Effendy ${ }^{4)}$, Lilis Amalia ${ }^{5)}$ \\ ${ }^{1,2)}$ UPBJJ-UT Surabaya, Universitas Terbuka \\ Kampus C Unair Mulyorejo, Surabaya \\ ${ }^{1)}$ sugiran-sby@ut.ac.id \\ ${ }^{2)}$ pardameandaulay@ut.ac.id \\ ${ }^{3,4)}$ Program Studi Sistem Informasi, Fakultas Sains dan Teknologi, Universitas Airlangga \\ Kampus C Unair Mulyorejo, Surabaya \\ ${ }^{3)}$ badruszaman@fst.unair.ac.id \\ 4)faried-e@fst.unair.ac.id \\ ${ }^{5)}$ Program Studi Diploma Sistem Informasi, Fakultas Vokasi, Universitas Airlangga \\ Jl. Srikana 65 Surabaya \\ ${ }^{5)}$ lilis.amalia-12@fst.unair.ac.id
}

\begin{abstract}
Abstrak- Penjaminan kinerja tutor di Universitas Terbuka (UT) ditentukan dari hasil evaluasi tutor yang dilakukan secara manual dengan cara membagikan angket kepada mahasiswa. Sistem ini membutuhkan biaya besar, kurang disukai mahasiswa, mengganggu aktivitas tutorial, pengolahan angket masih dilakukan secara manual, dan laporan hasil tidak dapat diterima tepat waktu. Solusinya perlu sistem evaluasi tutor berbasis online untuk menggantikan sistem yang lama. Penelitian ini bertujuan untuk menghasilkan aplikasi sistem evaluasi tutor berbasis online yang dapat meningkatkan kualitas layanan Tutorial Tatap Muka di UT. Desain aplikasi menggunakan System Development Life Cycle (SDLC) dengan beberapa tahapan. Tahap pertama adalah analisis kebutuhan menggunakan teknik wawancara, dokumentasi dan observasi. Tahap kedua adalah analisis kebutuhan sistem yang dilakukan untuk merumuskan solusi dari permasalahan yang ada. Tahap ketetiga yaitu perancangan sistem yang digambarkan dalam bentuk diagram data flow diagram context level (DFD). Tahap keempat merupakan implementasi sistem yang dilakukan dengan membuat pseudocode. Tahap terakhir adalah pengujian sistem, menggunakan metode black box testing. Hasil ujicoba menunjukkan bahwa aplikasi sistem sudah sesuai dengan kebutuhan, dimana mahasiswa UT dapat menilai tutor dengan mengakses internet. Berdasarkan pengujian fungsional dan evaluasi aplikasi evaluasi tutor berbasis online ini dapat membantu UT dalam hal peningkatan kualitas layanan tutorial tatap muka.
\end{abstract}

Kata Kunci-Sistem Evaluasi Tutor, Tutorial Tatap Muka, Pendidikan Jarak Jauh, Universitas Terbuka

Abstract - Underwriting performance of tutors at the Open University (UT) is determined from the evaluation of tutors is done manually by distributing a questionnaire to students. This system is costly, less preferred students, interfere with the activity of the tutorial, the questionnaire processing is still done manually, and the report can not be received on time. The solution needs to be an evaluation system based tutors online to replace the old system. This study aims to generate application-based tutor online evaluation system which can improve the quality of service tutorial face to face at UT. Application design using the System Development Life Cycle (SDLC) with several stages. The first is a systems planning (needs analysis), using interview techniques, dokuemntasi and observation. Second, system analysis (system requirements analysis) conducted to formulate the solution of existing problems. Third, the system design (system design), which is depicted in diagrammatic form context-level data flow diagram (DFD). Fourth systems implementation (implementation of the system), carried out using pseudocode programming code based on the programming language, and Fifth, system testing, using black box method testing. Results test show that the application is in conformity with the needs of the system, where students can assess the tutor UT simply by accessing the internet. Expected results of this study, evaluation of the application form based online tutors can help UT in terms of improving the quality of face-to-face tutorial services.

Keywords-Tutor Evaluation System, Face to Face Tutorial, Distance Education, Open University

Article history:

Received 8 November 2015; Received in revised form 7 December 2015 \& 2 March 2016; Accepted 10 March 2016; Available online 30 April 2016

\section{PENDAHULUAN}

Universitas Terbuka (UT) merupakan salah satu perguruan tinggi negeri di Indonesia yang menyelenggarakan sistem pembelajaran terbuka dan jarak jauh. Dalam sistem pembelajaran seperti ini, mahasiswa tidak perlu wajib hadir ke kampus, tetapi mereka dituntut belajar mandiri dari bahan 
ajar (modul) yang telah disediakan sesuai dengan waktu dan kesempatan masing-masing. Sistem belajar seperti ini terbukti efektif untuk meningkatkan daya jangkau dan pemerataan kesempatan pendidikan bagi semua warga negara Indonesia termasuk mereka yang tinggal di daerah terpencil. Namun, kenyataannya belum semua mahasiswa UT mampu mengikuti sistem belajar mandiri sehingga banyak diantara mereka yang mengalami masalah.

Adapun beberapa masalah yang sering dihadapi mahasiswa UT adalah kesulitan memahami bahan ajar, merasa terisolasi, dan lambat memperoleh feedback pada tugas-tugas yang dikerjakan (Andriani, 2005). Munculnya masalah-masalah tersebut diakibatkan mereka belum terbiasa dengan sistem belajar jarak jauh dan sebaliknya sudah terbiasa belajar tatap muka dengan bimbingan seorang guru di kelas sebagaimana yang dialaminya sewaktu belajar di tingkat sekolah sebelumnya. Oleh karena itu, mahasiswa yang belajar pada pendidikan jarak jauh, masih memerlukan bantuan akademik dalam bentuk layanan tutorial (Wardani, 2000).

Tutorial merupakan salah satu bentuk layanan bantuan belajar yang diberikan kepada mahasiswa untuk membantu mahasiswa mencapai hasil belajar secara optimal. Ada beberapa jenis layanan tutorial yang diselenggarakan di UT, yaitu tutorial tertulis, tutorial melalui internet, tutorial radio, dan tutorial tatap muka (TTM). Pada umumnya layanan tutorial tersebut menggunakan sarana multimedia atau media elektronik, sehingga diperlukan kemampuan tutor menyajikan materi dalam bentuk tulisan, dan menyampaikannya kepada mahasiswa melalui berbagai media yang tepat. Berbeda dengan jenis tutorial lain, TTM membutuhkan kehadiran seorang tutor untuk bertatap muka dengan mahasiswa pada saat berlangsungnya kegiatan tutorial. Dalam hal ini, ketersediaan tutor dianggap sebagai salah satu komponen penting dalam penyelenggaraan TTM.

Untuk memenuhi ketersediaan tutor, selama ini UT melakukan rekrutment tutor tidak terbatas dari kalangan internal saja, tetapi pada umumnya berasal dari luar UT, yaitu mereka yang memiliki profesi sebagai dosen pada perguruan tinggi lain, widyaswara, guru SMU, PNS atau tenaga kependidikan pada Dinas Pendidikan setempat, praktisi/karyawan dalam bidang tertentu yang dibutuhkan atau terkait dengan materi yang perlu dipelajari oleh mahasiswa, seperti IGTKI (khusus untuk tutor PAUD). Tutor dari luar UT ini biasanya bekerja sebagai tenaga lepas atau kontrak kerja (Padmo, 2004)

Namun, hasil evaluasi dan monitoring yang dilakukan selama ini, kebanyakan tutor dari luar UT seringkali menyamakan kegiatan tutorial dengan perkuliahan tatap muka seperti pada institusi tempat mereka bertugas. Padahal tugas tutor jauh lebih berat, yaitu: harus menyiapkan bahan-bahan yang sesuai untuk diajarkan, menguasai materi, mampu menjelaskan konsepkonsep materi, mampu berkomunikasi dengan mahasiswa, dan mampu membuat penilaian (progress) mahasiswa (Arends, 2011).

Terdapat lima variabel kinerja tutor yang harus dikuasai oleh tutor, yaitu; (1) persiapan tutorial, meliputi persiapan rencana tutorial, persiapan bahan tutorial, persiapan tugas untuk mahasiswa, (2) penguasaan materi tutorial sebagai bahan yang akan diberikan kepada mahasiswa, (3) kemampuan tutor menyajikan materi ajar, (4) kemampuan berkomunikasi dengan mahasiswa, (5) disiplin tutor menjalankan tugas, pemanfaatan waktu, pemberian tugas sesuai jadwal, dan mengumpulkan nilai tugas tepat waktu (Herman, 2010).

Untuk menjamin kinerja tutor, UT telah melakukan berbagai upaya, diantaranya melalui pengembangan standar dan prosedur layanan prima serta berbagai pelatihan, baik melalui modus tatap muka maupun jarak jauh, melakukan program akreditasi tutor agar seluruh tutor yang tersebar di seluruh Indonesia memiliki standar yang baku (Prastiti, 2011). Penjaminan kualitas tutor juga ditentukan dari hasil evaluasi tutor oleh mahasiswa (Sudirah, 2009). Hal ini dilakukan agar evaluasi tutor dapat dilakukan dengan baik dan objektif sesuai dengan keinginan dan kebutuhan mahasiswa sebagai konsumen utama layanan UT.

Didalam organisasi pendidikan tinggi, evaluasi dosen merupakan cara untuk mengetahui pengaruh pengajaran dosen terhadap mahasiswa (Wijaya \& Henny, 2012). Istilah lain yang sering digunakan adalah penimbangan karya, yaitu proses penilaian dari ciri-ciri kepribadian, perilaku kerja, dan hasil seorang tenaga kerja atau karyawan (pekerja dan manajer), yang dianggap menunjang unjuk kerjanya, yang digunakan sebagai bahan pertimbangan untuk pengambilan keputusan tentang tindakan-tindakan di bidang ketenagakerjaan. Evaluasi dosen meliputi kegiatan mengumpulkan informasi mengenai bagaimana dosen melakukan pekerjaan, menginterpretasi informasi dan membuat penilaian mengenai tindakan apa yang harus dilakukan untuk meningkatkan kualitas pengajaran.

Dalam rangka penjaminan mutu penyelenggaraan proses tutorial tatap muka (TTM), Unit Program Belajar Jarak Jauh (UPBJJ) UT Surabaya sebagai unit pelaksana teknis pembelajaran (tutorial), selama ini memberikan kesempatan luas kepada mahasiswa untuk terlibat di dalam evaluasi proses tutorial. Evaluasi oleh mahasiswa dilakukan secara berkala dan berkesinambungan setiap tahapan tutorial dengan menggunakan instrumen "Angket Evaluasi Tutor oleh Mahasiswa" (UM00-RK03). Instrumen angket didistribusikan ke seluruh mahasiswa di 18 
kabupaten dan kota di wilayah jangkauan UPBJJUT Surabaya. Angket dianalisis dan dievaluasi oleh Tim Monev Tutorial UPBJJ-UT Surabaya, dan merumuskan kemungkinan perlunya tindakan perbaikan dan pencegahan. Hasilnya dilaporkan kepada manajemen UPBJJ-UT Surabaya untuk dievaluasi dan ditindaklanjuti, bagi penjaminan dan peningkatan mutu tutorial pada periode tutorial selanjutnya.

Namun pelaksanaan evaluasi tutor sulit dilakukan karena jumlah tutor yang harus dievaluasi cukup banyak dan lokasi tutorial yang tersebar di berbagai wilayah kabupaten/kota. Berdasarkan data tutor yang terdokumentasi di dalam Aplikasi Tutor UPBJJ-UT Surabaya, pada tahun 2014 jumlah tutor sebanyak 1.187 orang dengan kualifikasi pendidikan tutor bisa dilihat pada table 1 .

TABel 1. KuAlifikasi Pendidikan Tutor

\begin{tabular}{|l|c|c|}
\hline $\begin{array}{l}\text { Kualifikasi } \\
\text { Pendidikan }\end{array}$ & Jumlah & Persentae \\
\hline Sarjana & 294 & 25 \\
\hline Magister (S-2) & 826 & 70 \\
\hline Doktor (S-3) & 67 & 5 \\
\hline & 1.187 & 100 \\
\hline
\end{tabular}

Sumber: Aplikasi Tutorial UPBJJ-UT Surabaya, 2014

Mengingat jumlah tutor yang harus dievaluasi cukup banyak, jumlah mahasiswa dan mata kuliah yang diambil juga cukup banyak, maka sistem evaluasi tutor yang dilakukan selama ini dinilai belum efektif dan efisien. Ketidakefektifan terlihat dari banyaknya kegiatan yang harus dilakukan, seperti pembagian angket, mengumpulkan, menghitung, melakukan analisis hasil angket, dan membuat laporan. Sementara itu, ketidakefisienan menyangkut pada besarnya biaya untuk mengcopy angket dan hal ini tidak sesuai dengan prinsip go green yang menjadi motto UT. Selain itu, secara psikologis ada kecemasan dari mahasiswa apabila mengisi angket karena perasaan takut terhadap tutor yang sedang dinilai.

Solusi yang ditawarkan untuk menyelesaikan permasalahan tersebut adalah dengan membangun aplikasi sistem evaluasi tutor berbasis online, di mana mahasiswa dapat mengisi angket dengan cara mengakses internet baik menggunakan komputer maupun telepon genggam. Aplikasi seperti ini sebenarnya sudah lazim digunakan oleh perusahaan dan di dunia pendidikan untuk memberikan penilaian kepada semua aspek kegiatan yang dikelola. Bahkan, di era media sosial saat ini, pengumpulan data tentang persepsi, pandangan, sikap khalayak yang sebelumnya harus digali lewat penelitian lapangan yang berbiaya tinggi bisa diperoleh cukup tersambung ke internet (Rahmawati \& Ahdiat, 2014).

Kemudahan-kemudahan tersebut ditunjang dengan adanya situs penyedia layanan pembuatan survey, seperti SurveyMonkey yang sering digunakan untuk survei tentang kepuasan konsumen atas pelayanan/produk bisnis (customer satisfaction questionnaire), kualitas brand suatu produk di mata pelanggan (brand awareness), harga terbaik seperti apa yang diterima pasar (price testing), ide-ide bisnis baru apa yang tengah populer di pasaran (concept testing), dan meneliti tentang kompetitor/pesaing (competitor research).

Sementara itu, di dunia pendidikan, beberapa universitas juga telah menggunakan evaluasi layanan akademik maupun nonakademik dengan memanfaatkan internet. Namun, evaluasi yang dilakukan bukan untuk menilai produk, tetapi lebih banyak untuk kepentingan pengukuran dan perbaikan proses pembelajaran. Misalnya, di Universitas Indonesia ada kewajiban bagi mahasiswa untuk menilai kinerja dosen dalam proses pembelajaran pada setiap akhir semester dengan memanfaatkan akses internet.

Beberapa penelitian yang dilakukan untuk mengembangkan aplikasi sistem evaluasi untuk keperluan pembelajaran sudah banyak dilakukan misalnya (Syamsiyah, 2015) (Sidiq, 2009) (Kertiasih, Setemen, Suputra, \& Marti, 2015) dan (Wijaya \& Henny, 2012). Berdasarkan beberapa hasil penelitian tersebut menunjukkan bahwa pengembangan aplikasi evaluasi berbasis web sudah banyak dilakukan, namun tampaknya masih terbatas pada perguruan tinggi tatap muka, sedangkan pada perguruan tinggi jarak jauh, seperti di UT belum pernah dilakukan. Padahal, UT memiliki jumlah mahasiswa yang banyak dan tersebar di seluruh Indonesia, maka sistem evaluasi tutor berbasis online ini bisa menjadi solusi teknologi yang diharapkan dapat meningkatkan kualitas layanan tutorial tatap muka. Selain itu aplikasi ini dapat membantu penyusunan jadwal tutorial karena sistem ini juga dapat merekomendasikan nama-nama tutor yang bisa memberi tutorial pada semester berikutnya. Aplikasi ini akan berguna dalam meningkatkan kualitas tutor dan upaya meningkatkan layanan bantuan belajar kepada mahasiswa.

\section{METODE PENELITIAN}

Pengembangan sistem evaluasi tutor berbasis online dilakukan dengan memodifikasi metode System Development Life Cycle (SDLC), yang terdiri dari 6 tahapan, yaitu; systems planning (tahap perencanaan), systems analysis (tahap analisa), systems design (tahap perancangan), systems implementation (tahap implementasi), dan System testing (tahap pengujian).

\section{A. Systems Planning (Tahap Perencanaan)}

Tahap perencanaan atau disebut juga tahap identifikasi kebutuhan dilakukan untuk mendapatkan data dan informasi terkait dengan kegiatan evaluasi tutor oleh mahasiswa yang selama ini dilakukan di UT. Teknik yang digunakan dalam identifikasi kebutuhan adalah sebagai berikut: 
1) Wawancara: wawancara dilakukan dengan calon pengguna aplikasi sistem, yaitu; mahasiswa, tutor, dan pegawai tata usaha untuk memperoleh data dan informasi terkait kegiatan evaluasi tutor yang selama ini digunakan.

2) Studi dokumentasi : mempelajari berkasberkas yang terkait dengan sistem evaluasi tutor yang selama ini digunakan.

2) Observasi: melihat secara langsung prosedur-prosedur yang digunakan dalam kegiatan evaluasi tutor yang selama ini dilakukan. Data yang terkumpul dijadikan sebagai acuan untuk merevisi aplikasi yang akan dikembangkan untuk mendapatkan hasil akhir yang diinginkan.

\section{B. System Analysis (Analisis Kebutuhan Sistem)}

Informasi yang terdapat dalam dokumen analisis kebutuhan, akan menjadi referensi di tahap analisis sistem ini. Data yang telah teridentifikasi selanjutnya dianalisa dan kemudian merumuskan solusi yang paling tepat untuk memecahkan permasalahan yang ada. Dalam tahap ini hal-hal yang perlu dianalisis adalah hambatan yang dialami oleh pengguna, dan fungsi yang ditangani sistem.

\section{System Design (Perancangan Sistem)}

Pada tahapan perancangan sistem dilakukan menggunakan metode berorientasi obyek yang digambarkan dalam bentuk diagram jenjang (Hieracy Chart) dan data flow diagram context level (DFD). Diagram-diagram tersebut digunakan sebagai acuan dalam pembangunan sistem. Desain sistem yang dilakukan dalam penelitian ini meliputi desain model, desain database serta desain input dan output.

\section{System Implementation (Sistem Implementasi)}

Tahap implementasi merupakan penerapan dari sistem yang telah dibangun sebelumnya dengan menggunakan perangkat lunak maupun perangkat keras. Implementasi sistem dilakukan dengan menggunakan kode pemrograman pseudocode berbasis pada bahasa pemrograman, sehingga mudah untuk menggambarkan algoritma yang akan dikomunikasikan kepada programmer. Prosedur penggunaan sistem digambarkan melalui bagan alir sistem (sistem flowchart) dan form input dan output.

\section{E. System Testing (Tahap Pengujian)}

Untuk menjamin bahwa persyaratan sistem (pada tahap pertama) telah dipenuhi dilakukan tahap pengujian sistem. Uji coba sistem bertujuan untuk mengetahui apakah sistem dapat berjalan dengan baik atau tidak, dan mengetahui seberapa banyak kesalahan yang ada pada sistem. Apabila terdapat kesalahan, maka sistem akan diperbaiki dan diuji kembali. Pengujian sistem dilakukan menggunakan black box testing, yaitu mengamati hasil eksekusi melalui data uji dan memeriksa fungsional dari perangkat lunak. Selain itu, ujicoba sistem juga dilakukan dengan meminta pendapat dua orang pakar yang sekaligus bertugas untuk memvalidasi rancangan aplikasi sistem. Kriteria pakar yang digunakan adalah dosen bidang teknologi informasi dengan kualifikasi minimal bergelar master dibidang teknologi informasi.

\section{HASIL DAN PEMBAHASAN}

\section{A. Hasil Identifikasi Kebutuhan}

Identifikeasi kebutuhan dilakukan dengan beberapa tekinik yaitu wawancara, studi dokumentasi dan observasi. Berikut adalah hasil dari tahapan identifikasi kebutuhan.

1) Wawancara: hasil wawancara menunjukkan bahwa meskipun sistem pendidikan jarak jauh membatasi kontak langsung antara mahasiswa dengan dosen, tetapi mahasiswa UT masih menaruh harapan besar terhadap adanya penyelenggaraan layanan tutorial tatap muka dan berharap agar tutor yang memberi tutorial adalah orang-orang yang memiliki kualitas yang baik. Idealnya Unit Program Belajar Jarak Jauh (UPBJJ) UT Surabaya mencetak kuisioner sesuai jumlah mahasiswa yang ada. Namun, jumlah mahasiswa UT yang cukup banyak, maka kuesioner yang diperbanyak hanya untuk perwakilan mahasiswa. Jika mengcoy kuesioner untuk seluruh mahasiswa membutuhkan dana yang cukup besar. Untuk mengurangi biaya tersebut, selama ini hanya perwakilan mahasiswa saja di setiap kelas yang dimintai untuk mengisi kuisioner. Proses evaluasi tersebut secara ekonomis memang dapat menghemat dana atau anggaran UT, tetapi di sisi yang lain kurang mencerminkan nilai-nilai demokrasi, bahkan ada penilaian dari mahasiswa yang tidak terakomodasi sehingga tujuan evaluasi tutor untuk memperoleh feedback perbaikan program terutama kualitas dan kinerja tutor tidak tercapai. Secara psikologis, hambatan yang sering dihadapi adalah munculnya kecemasan pada mahasiswa karena meskipun tidak menantumkan nama, tetapi tutor dan pegawai UT masih bisa menelusuri melalui pencocokan tandan tangan. Untuk itu, perlu sistem evaluasi tutor yang baru dengan memanfaatkan teknologi internet.

2) Studi dokumentasi, menunjukkan bahwa berbagai prosedur dalam kegiatan evaluasi tutor yang digunakan selama ini membutuhkan biaya besar dan waktu yang lama sehingga sering sekali laporan hasil kuesioner tidak digunakan sebagai acuan dalam penyusunan jadwal tutorial. Prosedur pelaksanaan evaluasi tutor oleh mahasiswa UT mengacu kepada pedoman Simintas UT, dimana angket kuisioner diperoleh dari UT Pusat yang berisi tentang daftar pertanyaan yang harus diisi oleh mahasiswa. Setiap akhir tutorial, mahasiswa melakukan evaluasi tutor dalam bentuk kuesioner. 
TABEL 2. HAMBATAN SISTEM EVALUASI TUTORIAL SECARA MANUAL

\begin{tabular}{|c|c|c|c|c|}
\hline Pencetakan Kuesioner & Pembagian Kuesioner & Pengisian Kuesiner & Pengolahan & Jadwal Tutorial \\
\hline $\begin{array}{l}\text { - Mudah terselip } \\
\text { - butuh waktu lama } \\
\text { - Butuh biaya banyak } \\
\text { - Kontradiktif dengan } \\
\text { slogan "go green" }\end{array}$ & $\begin{array}{lr}\text { - tidak } & \text { semua } \\
\text { mahasiswa } & \text { diberi } \\
\text { angket } & \\
\text { - Jumlah } & \text { Petugas } \\
\text { sedikit } & \\
\text { - Proses pembagian } \\
\text { - lama }\end{array}$ & $\begin{array}{l}\text { - Butuh waktu lama } \\
\text { - Mengganggu } \\
\text { kegiatan tutorial } \\
\text { - Rasa takut dengan } \\
\text { tutor }\end{array}$ & $\begin{array}{l}\text { - Laporan } \\
\text { manual } \\
\text { - Butuh waktu } \\
\text { lama } \\
\text { - Hasil } \\
\text { diperoleh lama }\end{array}$ & $\begin{array}{l}\text { - mengganggu } \\
\text { penyusunan jadwal } \\
\text { tutorial } \\
\text { - menunggu hasil laporan } \\
\text { evaluasi tutorial } \\
\text { - Penysunan jadwal } \\
\text { masih manual }\end{array}$ \\
\hline
\end{tabular}

Setelah angket dibagikan dan diisi, petugas penanggung jawab wilayah mengumpulkan hasil tersebut mulai dari setiap kelompok belajar, kabupaten dan dikumpulkan ke UPBJJ-UT Surabaya. Kuisioner yang sudah diisi dihitung menggunakan hitungan manual menggunakan spread sheet. Petugas harus memasukkan data satu persatu kemudian menghitung jumlah dan ratarata dari daftar pertanyaan. Hasil perhitungan dikumpulkan dan diserahkan kepada Koordinator BBLBA. Selanjutnya, Koordinator BBLBA akan melakukan rekapitulasi data dengan menggunakan program Microsoft Exel. Data tersebut diolah menjadi sebuah laporan berupa grafik pencapaian tutor selama memberikan tutorial di kelas. Dari hasil grafik itulah dapat diketahui bagaimana kinerja masing-masing tutor. Laporan evaluasi tutor yang telah selesai dibuat akan diarsipkan ke dalam sebuah lemari arsip.

3) Observasi, evaluasi tutor dilakukan setiap semester dengan cara mengedarkan angket kepada pengurus pokjar, kemudian dibagikan kepada mahasiswa. Angket kuisioner didapatkan dari UT Pusat yang berisi tentang daftar pertanyaan yang harus diisi oleh mahasiswa. Sebelum diedarkan, pihak UPBJJ-UT Surabaya mencetak kuisioner sebanyak jumlah mahasiswa. Namun faktanya, jumlah mahasiswa yang cukup banyak sehingga petugas hanya memperbanyak sesuai jumlah kebutuhan saja. Dalam hal ini, hanya perwakilan mahasiswa pada setiap kelas yang diminta untuk mengisi kuisioner. Setelah diisi oleh mahasiswa, kuesioner dikumpulkan kembali kemudian dihitung secara manual menggunakan spread sheet. Petugas memasukkan data satu persatu dan menjumlahkan rata-rata dari hasil kuesioner. Data yang telah diolah kemudian dibuatkan dalam sebuah laporan berupa grafik pencapaian tutor. Dari laporan tersebut dapat diketahui tutor mana yang layak dan tidak layak, kemudian tutor yang memperoleh nilai layak akan direkomendasikan untuk memberi tutor pada semester berikutnya. Sistem evaluasi ini memiliki beberapa hambatan, diantaranya, pencetakan kuesioner, pembagian kusioner, pengisian kuesioner, pengolahan hasil, dan penyusunan jadwal tutorial. Selengkapnya dapat dilihat dalam Tabel 2.

Berdasarkan tabel 2 menunjukkan selama ini ada 5 (lima) hambatan yang sering dihadapi dalam pelaksanaan evaluasi tutor, yaitu; pencetakan kuesioner, pengisian kuesioner, pengolahan hasil, dan penyusunan jadwal tutorial. Temuan ini

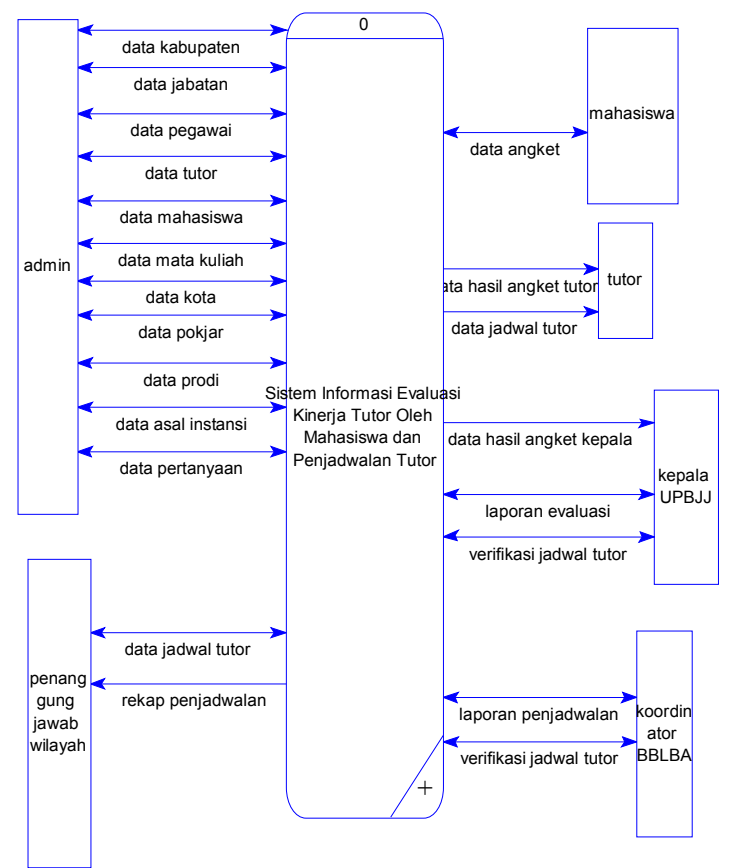

Gambar 1. Context Diagram 


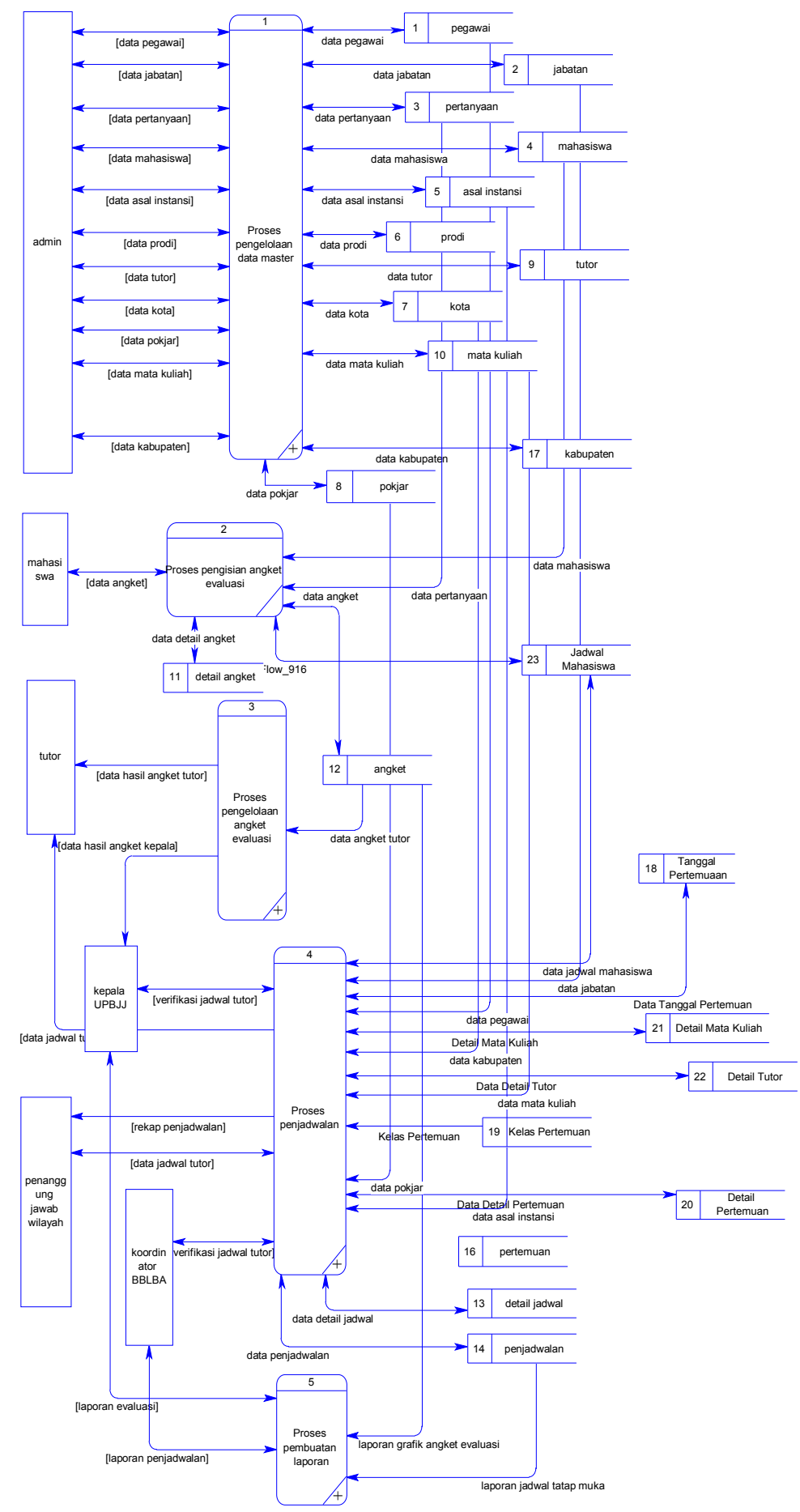

Gambar 2. DFD level 0

mendukung hasil penelitian yang menyatakan bahwa evaluasi manual dengan menggunakan instrumen angket memiliki banyak kelemahan, diantaranya; Pertama, evaluasi manual memerlukan waktu dan biaya yang cukup banyak untuk memproduksi instrumennnya. Kedua, proses pemeriksaan evaluasi dengan instrumen tercetak cukup rumit, sehingga memerlukan waktu bayak dan cenderung membosankan. Ketiga, secara psikologis evaluasi tutor menimbulkan kecemasan, meskipin tanpa mencantumkan identitas, namun diyakini masih dapat ditelusuri melalui pencocokan tulisan tangan (Kertiasih, Setemen, Suputra, \& Marti, 2015).

\section{B. Hasil Analisis Kebutuhan}

Data dan informasi yang diperoleh dari proses idntifikasi kebutuhan selanjutnya dianalisis. Hasil dari analisis kebutuhan adalah sebagai berikut: 


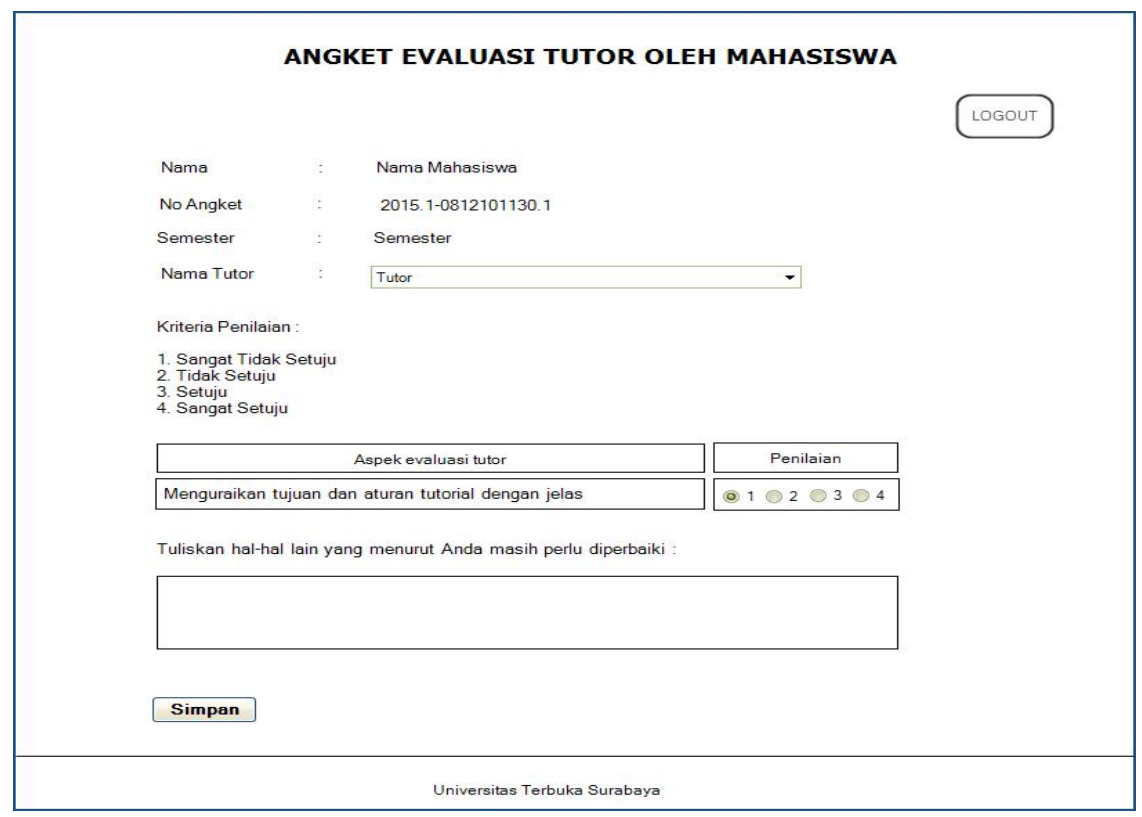

Gambar 3. Desain form angket evaluasi

1) Fitur yang dibutuhkan: berbagai hambatan yang dialami pada sistem evaluasi tutor yang selama ini digunakan, maka sistem evaluasi tutor berbasis online perlu dikembangkan. Dalam perancangan aplikasi ini, hal yang menjadi perhatian utama adalah kemudahan pengguna dalam mengoperasikan aplikasi tersebut. Untuk merancang model evaluasi tutor berbasis online ini, ada beberapa tahap yang harus dilakukan, yaitu diagram jenjang (Hieracy Chart). Perancangan basis data pada Aplikasi Evaluasi tutor berbasis online dapat dilihat pada gambar 1 .

2) Prosedur baru: berdasarkan fitur yang sudah didefinisikan, prosedur atau urutan kegiatan evaluasi tutor mengalami beberapa perubahan. Prosedur proses evalusi tutor yang baru adalah sebagai berikut:

a) Prosedur Pengelolaan Angket Evaluasi. Penghitungan jumlah secara otomatis oleh sistem berdasarkan pertanyaan pada evaluasi. Menghasilkan jumlah yang akan dikonfersikan ke dalam bentuk diagram batang. Diagram batang menampilkan hasil penilaian evaluasi setiap mata kuliah yang diampu seorang tutor dalam satu semester berdasarkan satu prodi.

b) Pengelolaan Data Master, admin login ke ke sistem. Untuk memasukkan data baru, admin memasukkan data ke form inputan yang telah tersedia, kemudian klik button simpan untuk menyimpan data yang sudah diisikan. Untuk mengubah dan menghapus data, admin membuka halaman form yang terdapat tabel yang terdapat navigasi edit dan delete. Klik button edit untuk mengubah data. Isikan field yang ingin dirubah, llik button simpan untuk menyimpan data yang sudah dirubah. c) Prosedur Pengisian Angket Evaluasi. Mahasiswa login ke ke sistem. Mahasiswa memilih nama mata kuliah berserta nama tutor yang mengampu mata kuliah tersebut. Kemudian mahasiswa mengisi kuisioner berupa pertanyaan. Tekan tombol save untuk mengakhiri pengisian kuisioner dan hasilnya akan tersimpan ke sistem.

\section{Hasil Perancangan Sistem}

Hasil perancangan sistem menunjukkan bahwa semua user, yaitu administrator, tutor, dan mahasiswa harus melakukan login terlebih dahulu untuk mengakses perangkat lunak. Sistem akan melakukan verifikasi dan validasi. Apabila password salah, maka akan tampil informasi verifikasi, yaitu berupa pesan kesalahan. Administrator mengelola data tutor, mahasiswa, mata kuliah, kuesioner, mengubah password dan melihat hasil kuesioner. Mahasiswa dapat megubah password dan mengisi kuesioner. Desain aplikasi sistem evaluasi tutor ini disajikan dalam bentuk model logika yang digambarkan dengan menggunakan Data Flow Diagram (DFD). DFD sistem evaluasi tutor memiliki enam entitas, yaitu admin, penanggung jawab wilayah, Tutor, Kepala UPBJJ-UT Surabaya, Koordinator BBLBA, dan Mahasiswa. Objek-objek perancangan DFD digambarkan melalui Context diagram dan DFD Level 0. Context Diagram dapat ditunjukkan pada Gambar 1.

Dari context Diagram sistem yang diusulkan pada gambar 1 dapat diperinci lagi menjadi beberapa bagian yang akan digambarkan pada Data Flow Diagram (DFD) Level 0, yang dapat dijabarkan menjadi 5 proses, yakni proses pengelolaan data master, pengisian angket evaluasi, pengolaan angket evaluasi, proses penjadwalan dan proses pembuatan laporan. 


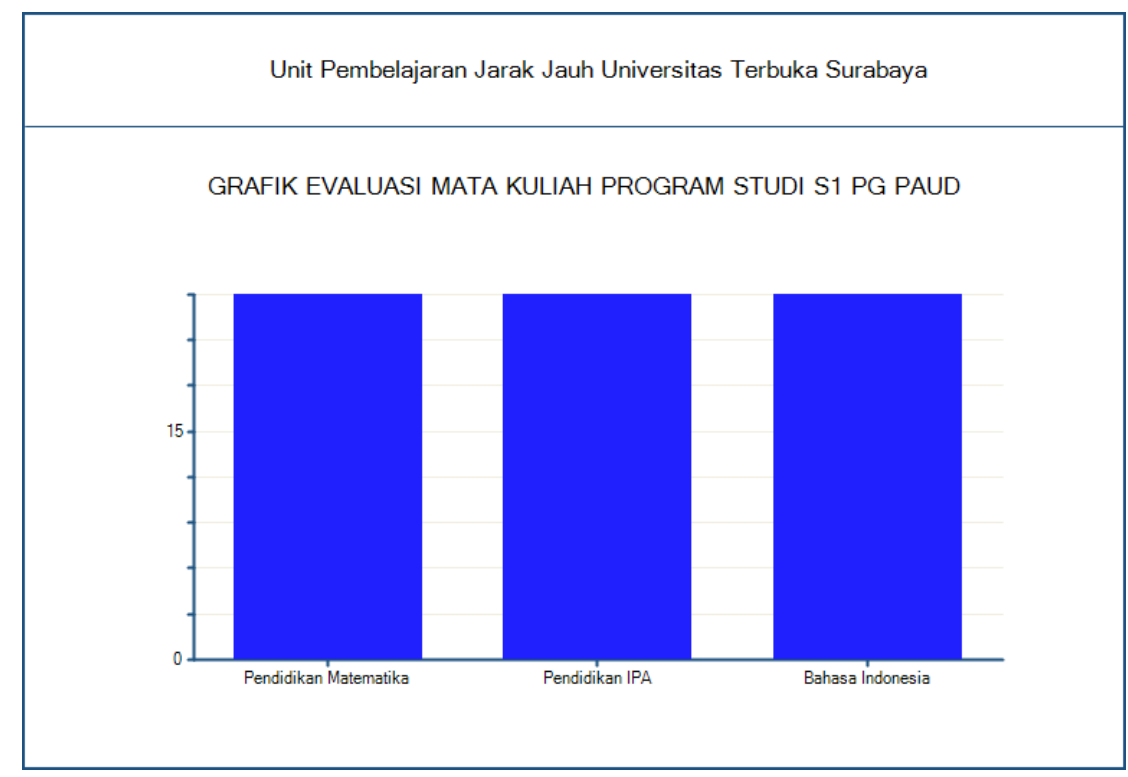

Gambar 4. Desain Output grafik laporan hasil evaluasi tutor

Diagram Level 0 selengkapnya ditunjukkan pada Gambar 2.

Rancangan sistem terakhir adalah desain input dan output. Desain input adalah desain yang digunakan untuk menerima masukan data yang akan disimpan ke dalam database dan akan digunakan ke dalam proses transaksi maupun sebagai output yang dilaporkan. Salah satu desain input yang berhasil dikembangkan adalah input data angket evaluasi terlihat pada Gambar 3.

Sementara itu, desain output aplikasi sistem evaluasi tutor ada dua, yaitu laporan grafik hasil evaluasi tutor dan laporan jadwal tutorial. Laporan grafik hasil evaluasi adalah laporan yang menjelaskan tentang hasil evaluasi yang diambil dari hasil penilaian angket yang telah diisi oleh mahasiswa. Sedangkan, laporan jadwal tutorial adalah dikeluarkan dari data pencatatan jadwal.

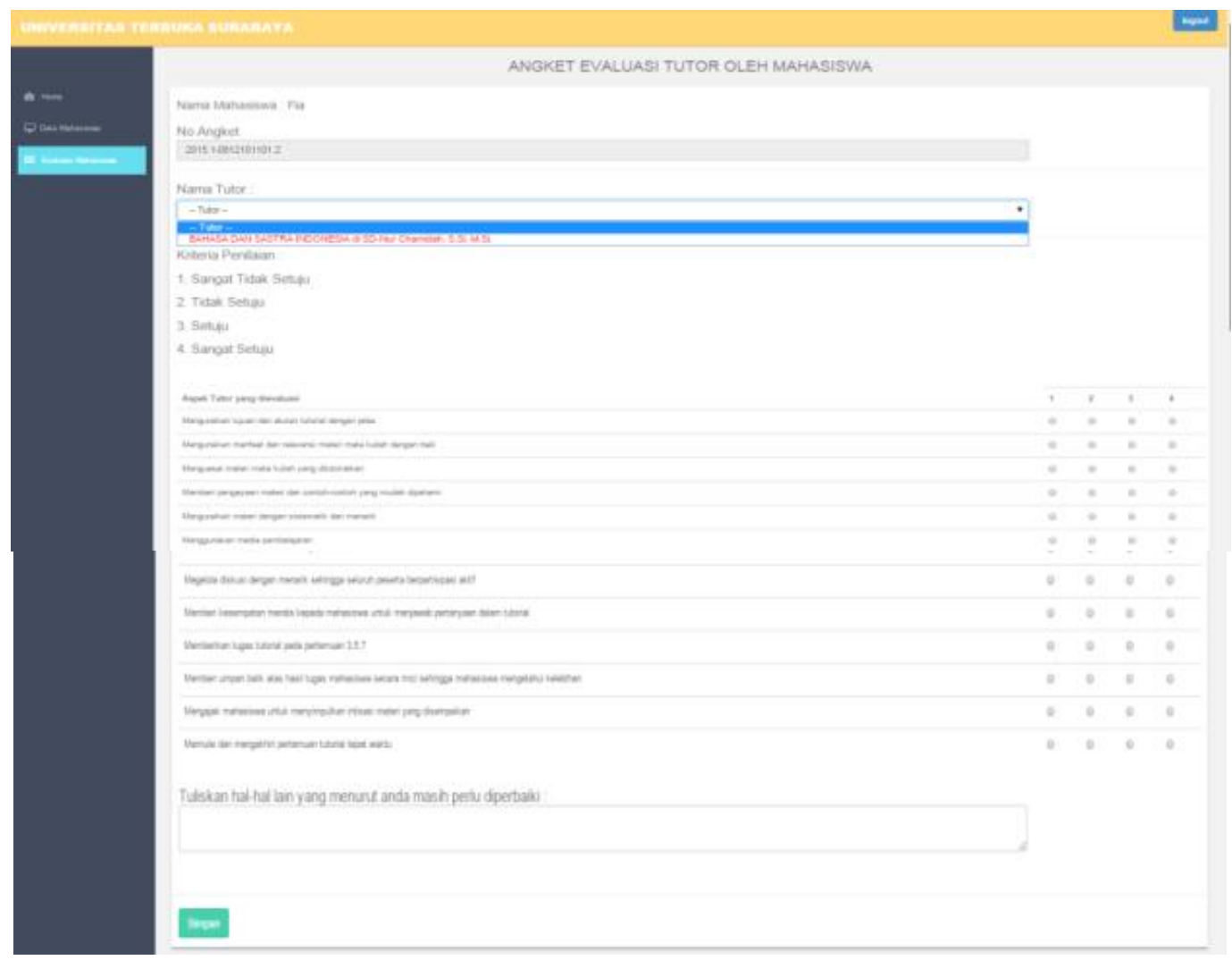

Gambar 5. Tampilan Pengisian Angket 
Desain ouput ditunjukkan pada Gambar 4.

\section{Hasil Implementation}

Ada beberapa tampilan form dalam aplikasi evaluasi tutor berbasis online, seperti halaman proses pengisian angket dapat dilihat pada Gambar 5.

Pseudocode pengisian angket evaluasi ini menjelaskan alur kerja sistem yaitu saat mahasiswa mengisikan data angket evaluasi. Pada proses ini terdapat input data sebagai berikut : Input : mengisikan data pada field angket, memberikan penilaian pada setiap aspek. Pseudocode pengisian angket evaluasi dapat dilihat pada Gambar 6 .

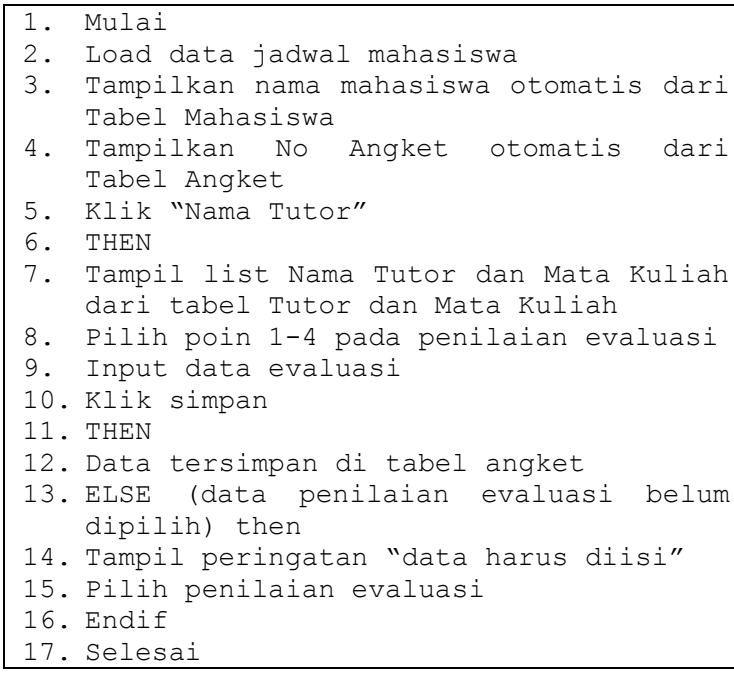

Gambar 6. Pseudocode pengisian angket

\section{E. Hasil Pengujian Sistem}

Pengujian sistem yang dilakukan meliputi: pengujian proses pengelolaan data master, proses pengisian angket evaluasi, proses pengelolaan angket evaluasi, proses penjadwalan, proses persetujuan penjadwalan, dan pembuatan laporan. Hasil uji coba sistem evaluasi tutor dapat dilihat pada Tabel 3.

Berdasarkan hasil ujicoba yang dilakukan dengan menggunakan black box testing diperoleh hasil bahwa sistem telah sesuai dengan kebutuhan yang diinginkan. Fungsi-fungsi yang ada pada sistem yang digunakan untuk mengelola data tutor, data mahasiswa, data matakuliah, data pertanyaan untuk evaluasi tutor sudah mewakili kebutuhan untuk melakukan evaluasi terhadap kinerja tutor guna meningkatkan kualitas layanan tutorial tatap muka pada pendidikan jarak jauh. Namun, untuk mendapatkan hasil yang lebih maksimal, evaluasi juga dilakukan oleh pakar bidang teknologi sistem informasi. Evaluasi pakar ini bertujuan untuk memvalidasi sistem dan sekaligus masukan untuk perbaikan selanjutnya.

Berdasarkan saran atau tanggapan yang disampaikan oleh pakar, digunakan untuk melakukan perbaikan hingga sistem ini layak untuk dipublikasikan kepada mahasiswa UT sebagai pengguna. Namun, sistem ini masih perlu disempurnakan agar aplikasi sistem dapat merekomendasikan tutor layak atau tidak dan melakukan uji coba produk kepada mahasiswa agar aplikasi sistem ini dapat dimanfaatkan secara meluas di UT.

TABel 3. Hasil Uji CoBa Sistem

\begin{tabular}{|c|c|c|c|}
\hline No & Input & Expected output & Hasil \\
\hline \multirow[t]{2}{*}{1} & $\begin{array}{c}\text { Memasukkan data } \\
\text { mahasiswa secara } \\
\text { lengkap }\end{array}$ & $\begin{array}{c}\text { Tampil data } \\
\text { mahasiswa baru }\end{array}$ & Sesuai \\
\hline & $\begin{array}{c}\text { Tidak memasukkan } \\
\text { data mahasiswa secara } \\
\text { lengkap atau tidak } \\
\text { sesuai }\end{array}$ & $\begin{array}{l}\text { Tampil notifikasi } \\
\text { /alert bahwa data } \\
\text { harus diisi }\end{array}$ & Sesuai \\
\hline \multirow[t]{2}{*}{2} & $\begin{array}{c}\text { Memasukkan data } \\
\text { angket evaluasi secara } \\
\text { lengkap }\end{array}$ & $\begin{array}{l}\text { Menyimpan data } \\
\text { angket ke database }\end{array}$ & Sesuai \\
\hline & $\begin{array}{c}\text { Tidak memasukkan } \\
\text { data angket evaluasi } \\
\text { secara lengkap atau } \\
\text { tidak sesuai }\end{array}$ & $\begin{array}{c}\text { Menampilkan } \\
\text { notifikasi/alert } \\
\text { bahwa data harus } \\
\text { diisi } \\
\end{array}$ & Sesuai \\
\hline \multirow[t]{2}{*}{3} & $\begin{array}{l}\text { Memasukkan data } \\
\text { penilaian tutor }\end{array}$ & $\begin{array}{l}\text { Menampilkan grafik } \\
\text { view dan laporan }\end{array}$ & Sesuai \\
\hline & $\begin{array}{l}\text { Tidak memasukkan } \\
\text { data penilaian tutor } \\
\text { atau tidak sesuai }\end{array}$ & $\begin{array}{c}\text { Menampilkan } \\
\text { notifikasi/alert } \\
\text { bahwa data harus } \\
\text { diisi }\end{array}$ & Sesuai \\
\hline \multirow[t]{2}{*}{4} & $\begin{array}{c}\text { Memasukkan data } \\
\text { penjadwalan secara } \\
\text { lengkap }\end{array}$ & $\begin{array}{c}\text { Menyimpan data } \\
\text { penjadwalan ke } \\
\text { database }\end{array}$ & Sesuai \\
\hline & $\begin{array}{l}\text { Tidak memasukkan } \\
\text { data penjadwalan } \\
\text { secara lengkap atau } \\
\text { tidak sesuai } \\
\end{array}$ & $\begin{array}{l}\text { Data tidak } \\
\text { tersimpan }\end{array}$ & Sesuai \\
\hline \multirow[t]{2}{*}{5} & $\begin{array}{l}\text { Menyetujui dengan } \\
\text { menggunakan klik } \\
\text { pada button setuju }\end{array}$ & $\begin{array}{c}\text { Mengupdate data } \\
\text { persetujuan ke } \\
\text { database }\end{array}$ & Sesuai \\
\hline & $\begin{array}{l}\text { Tidak memilih radio } \\
\text { button setuju pada } \\
\text { form atau tidak sesuai }\end{array}$ & Data tidak berubah & Sesuai \\
\hline \multirow[t]{2}{*}{6} & Klik button Cetak & $\begin{array}{c}\text { Menampilkan } \\
\text { laporan }\end{array}$ & Sesuai \\
\hline & $\begin{array}{c}\text { Tidak Klik button } \\
\text { cetak }\end{array}$ & $\begin{array}{c}\text { Laporan tidak } \\
\text { tampil }\end{array}$ & Sesuai \\
\hline
\end{tabular}

\section{KESIMPULAN}

Berdasarkan hasil pengujian rancangan sistem yang telah dibangun menunjukkan bahwa aplikasi sistem evaluasi tutor berbasis online telah sesuai dengan kebutuhan yang diinginkan. Sistem ini diharapkan mampu memberikan solusi terhadap berbagai hambatan yang dialami pada sistem evaluasi tutor dengan menggunakan angket yang selama ini diterapkan di UT, seperti mengefektifkan waktu pelaksanaan evaluasi tutor, mengefisienkan biaya produksi angket, mempermudah penghitungan dan penyusunan laporan, tidak mengganggu pelaksanaan tutorial dan secara psikologis diharapkan mengurangi kecemasan mahasiswa.

Beberapa hal yang diharapkan untuk dikembangkan agar rancangan sistem evaluasi tutor oleh mahasiswa bisa lebih bermanfaat adalah menyempurnakan aplikasi sistem yang dapat 
merekomendasikan tutor layak atau tidak untuk semester berikutnya. Melakukan uji coba produk kepada mahasiswa agar aplikasi sistem ini dapat dimanfaatkan secara meluas di UT.

\section{UCAPAN TERIMA KASIH}

Terima kasih kami kepada Direktorat Jenderal Pendidikan Tinggi Kementerian Riset Teknologi dan Pendidikan Tinggi yang telah membiayai penelitian Hibah Bersaing.

\section{DAFTAR PUSTAKA}

Andriani, D. (2005). Mahasiswa S2 pada sistem PJJ: pemanfatan Internet dan bantuan belajar. Jurnal Pendidikan Terbuka dan , 6 (2), 77-91.

Arends, R. I. (2011). Learning to Teach. New York: McGraw-Hill Education.

Herman. (2010). Penilaian peserta terhadap kinerja tutor, dan hasil tutorial dan biaya tutorial pada tutorial tatp muka di Universitas Terbuka. Jurnal Pendidikan Terbuka dan Jarak Jauh, , 11 (2), 84-98

Kertiasih, N. K., Setemen, K., Suputra, P. H., \& Marti, N. W. (2015). Pengembangan Sistem Evaluasi Untuk Dosen Sebagai Upaya Peningkatan Kualitas Pembelajaran. JPTK, UNDIKSHA , 12 (1), $27-34$

Padmo, D. (2004). Sistem Jaminan Kualitas pada Pendidikan Tinggi Jarak Jauh. Jakarta: Universitas Terbuka.
Prastiti, T. (2011). Evaluasi Program Pelatihan Tutor di Universitas Terbuka. Jurnal Evaluasi Pendidikan , 2 (2), 206-217.

Rahmawati, D., \& Ahdiat, A. (2014). Penelitian Sosial Digital : Menelaah kehidupan masyarakat di era teknologi informasi. Jakarta: Linea.

Sidiq, M. (2009). Pengembangan Sistem Informasi Evaluasi Kinerja Dosen Pada Fakultas Sains dan Teknologi UIN Syarif Hidayatullah. Skripsi, UIN Syarif Hidayatullah, Program Studi Sistem Informatika.

Sudirah. (2009). Model Pengembangan Kompetensi Tutor UT Berdasarkan Persepsi Tutor dan Alumni di UPBJJ Jakarta, Bogor, dan Serang. Disertasi, Institut Pertanian Bogor, Sekolah Pascasarjana .

Syamsiyah. (2015). Aplikasi Monitoring dan Evaluasi Perkuliahaan (Studi kasus Fakultas Sains dan Teknologi UIN Sunan Gunung Djati). Skripsi, UIN Sunan Gunung Djati, Program Studi Sistem Informatika.

Wardani, I. (2000). Program tutorial dalam sistem pendidikan tinggi terbuka dan jarak jauh. Jurnal Pendidikan Tinggi Jarak Jauh , 1 (2), 41 - 52.

Wijaya, A., \& Henny, J. (2012). Aplikasi Evaluasi Kinerja Dosen Berbasis Web Pada Sekolah Tinggi Teknik Musi. Seminar Nasional Teknologi Informasi \& Komunikasi Terapan 2012 (Semantik 2012) (pp. 481 - 486). Semarang: Universitas Diponegoro. 